\title{
Development and Evaluation of a Carbon Filter for Removing DMSO Vapor from the Exhaust of the W79 HE Dissolution Workstation
}

\author{
W. Bergman \\ K. Wilson \\ G.O. Nelson
}

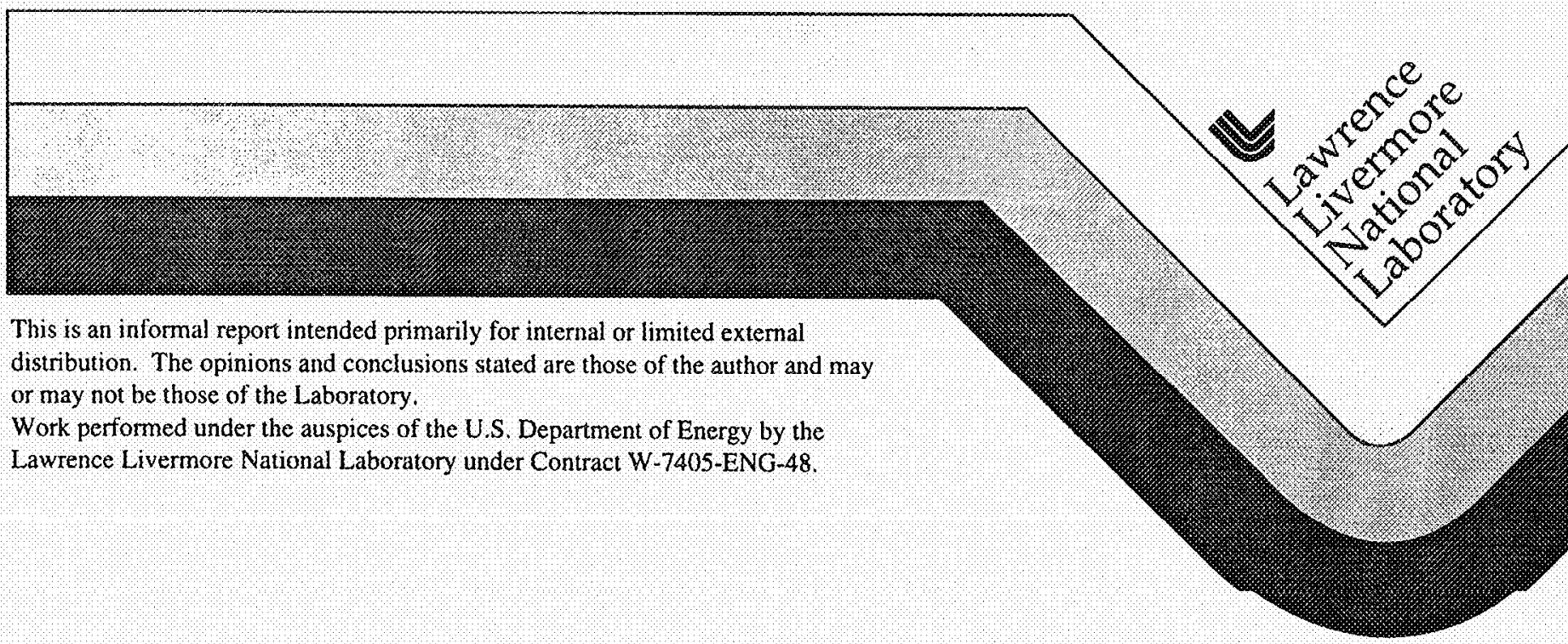




\section{DISCLADMER}

This document was prepared as an account of work sponsored by an agency of the United States Govemment Neither the United States Govemment nor the University of Califomia nor any of their emplovees, makes any warranty, express or implied, or assumes any legal bability or responsibility for the accuracy, completeness, or usefulness of any information, apparatus, product, or process disclosed, or represents that its use would not infringe privately owned rights. Reference herein to any specific commercal product, process, or service by trade name, trademark, manufacture, or othenwise, does not necessarily constitute or imply its endorsement, recommendation, or favoring by the Untted States Government or the University of Califomia. The views and opinions of authors expressed herein do not necessarily state or reflect those of the United States Govemment or the Unversity of Califomia, and shall not be used for advertising or product endorsement purposes.

This report has been reproduced directly from the best available copy.

Avallable to DOE and DOE contractors from the Office of Scientific and Technical Information

P.O. Box 62, Oak Ridge, TN 37831

Prices avalable from (123) 576.8401

A valable to the public from the National Technical Infonmation Senvee

US Department of Commerce 5285 Port Roval Rd, Springfeld $\mathrm{VA} 2101$ 
DEVELOPMENT AND EVALUATION OF A CARBON FILTER FOR REMOVING DMSO VAPOR FROM THE EXHAUST OF THE W79 HE DISSOLUTION WORKSTATION *

by

W. Bergman, K. Wilson, and G. O. Nelson ${ }^{1}$

Lawrence Livermore National Laboratory

Livermore, CA 94550

\begin{abstract}
We have developed and evaluated a carbon filter to remove dimethyl sulfoxide (DMSO) vapor from the exhaust of the W79 HE (high explosive)

Dissolution Workstation. A series of laboratory tests were conducted on eight different carbon samples to establish the vapor breakthrough curves and to select the best sample. Empirical equations were developed to predict the breakthrough curve for various air flows and bed thickness. These equations were used to design the filter cartridge. The filter consists of a cylindrical cartridge 12 inches high and 6 and 10 inches inside and outside diameter and has a pressure drop of 0.8 inches of water at $50 \mathrm{cfm}$. Experiments and computations verified the efficiency of the filter cartridge is greater than $99 \%$ at $35 \mathrm{cfm}$, and the carbon filter can process $60 \mathrm{HE}$ assemblies while maintaining greater than $90 \%$ efficiency before the carbon must be replaced.
\end{abstract}

\title{
Introduction
}

This study describes the development of a carbon filter that is a component of the exhaust system for the W79 HE Dissolution Workstation as shown in Figure 1. The Workstation is designed to support the DOE nuclear weapons dismantlement program in which hot DMSO sprays are used to dissolve the HE from HE assemblies. The description of the W79 Workstation and the complete air cleaning system is given in a previous report ${ }^{(1)}$. We developed the carbon filter because commercially available units were either designed for much larger ventilation systems or had excessive pressure drops. The typical ventilation filter has a 2' $\times 2$ ' cross sectional area and is designed for flow rates of $1,000 \mathrm{cfm}$ or greater. Smaller annular cartridge filters were developed for military vehicle applications but have pressure drops that greatly exceed the requirement of less than one inch of water at $50 \mathrm{cfm}$. In addition to the lack of suitable carbon filter units, there also is no information on the performance of carbon filters for removing DMSO vapors. Thus, we had to establish the basic adsorption. characteristics in addition to the design parameters to develop the DMSO carbon filter. The initial step was to demonstrate that activated carbon was effective in removing DMSO vapors.

*This work was performed under the auspices of the U.S. Department of Energy by Lawrence Livermore National Laboratory under contract No. W-7405-ENG-48.

${ }^{1}$ Miller-Nelson Research, Inc. 8 Harris Court, Suite C6, Monterey, CA, 93940 


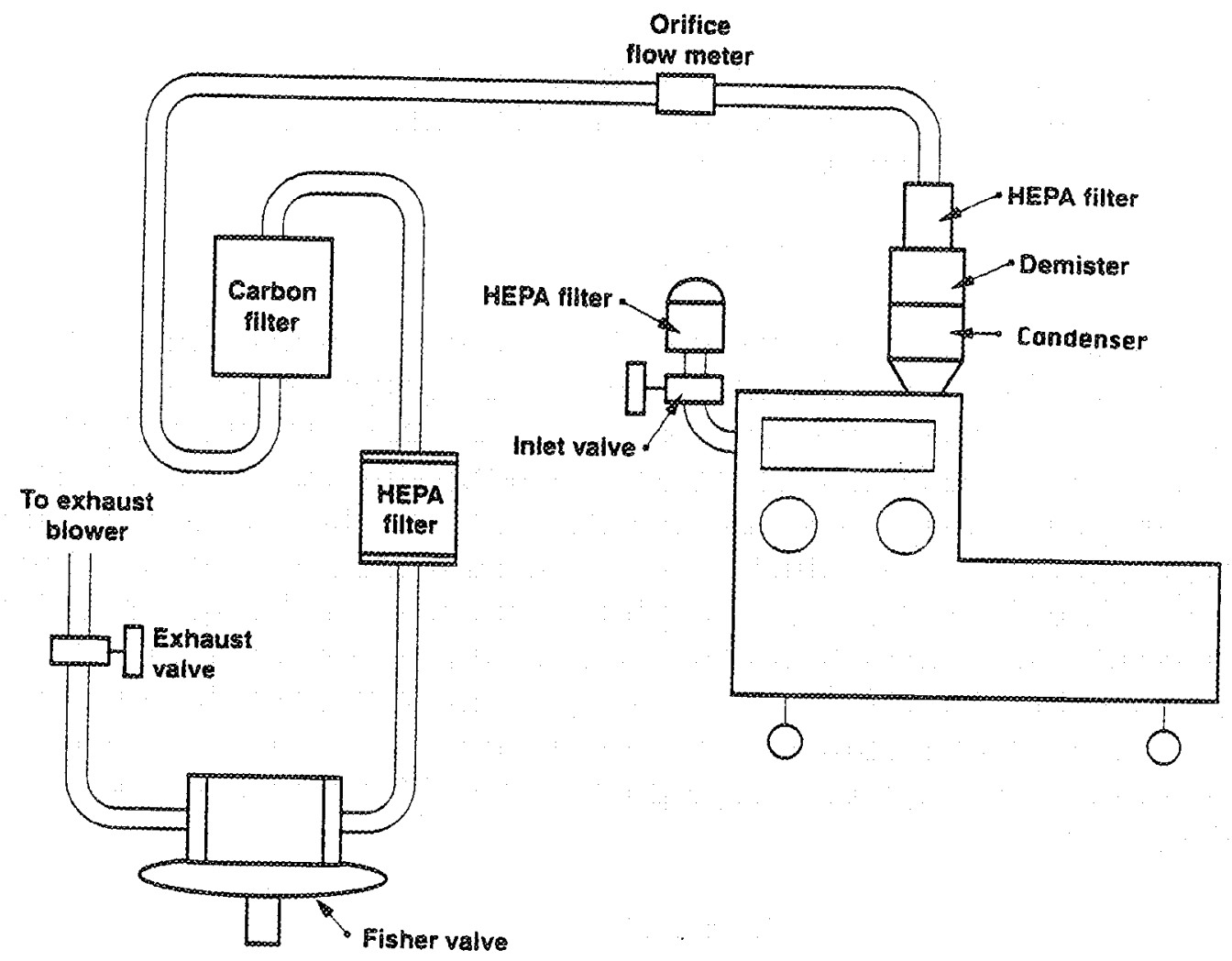

Figure 1. Schematic of exhaust system on the W79 HE Dissolution Workstation.

\section{Small Scale Laboratory Studies}

We conducted a survey test of eight different activated carbons to establish that activated carbon is effective in removing DMSO vapors and to identify the best carbon. The test carbons were packed into empty respirator cartridges having a total carbon volume of $112 \mathrm{cc}$, a diameter of $7.9 \mathrm{~cm}$ and a bed depth of $2.3 \mathrm{~cm}$. The cartridges were filled with carbon poured through a tube having multiple screens and a 2 feet free fall to insure tight packing. Each of the cartridges was weighed before and after the test to establish the weight of the carbon and the weight gain due to adsorbed DMSO vapor. The test consisted of passing 29.4 $1 /$ min air containing $500 \mathrm{ppm}\left(1.59 \times 10^{-3} \mathrm{~g} / \mathrm{l}\right)$ of DMSO vapor with less than $10 \%$ relative humidity at $25{ }^{\circ} \mathrm{C}$ through each cartridge. The DMSO vapor was generated by injecting a known flow of liquid DMSO using a calibrated syringe pump into a heated block that vaporized the liquid into a controlled air flow. The airflow rate corresponded to a flow velocity of $6 \mathrm{~m} / \mathrm{min}$ since the area was 49 
$\mathrm{cm}^{2}(4.9 \mathrm{l} / \mathrm{m})$. The airflow, gas temperature, and relative humidity were controlled with a Miller-Nelson flow control module. The efficiency of DMSO removal was determined by measuring the concentration of DMSO vapor before and after the cartridge using a Miran infrared analyzer (Foxborough Inc.). Since each of the tests was conducted until the carbon was saturated and had $0 \%$ efficiency, the increase in carbon weight represented the dynamic adsorption capacity of the carbon for DMSO. Figure 2 shows a schematic of the experimental apparatus used to conduct the small-scale carbon rests.

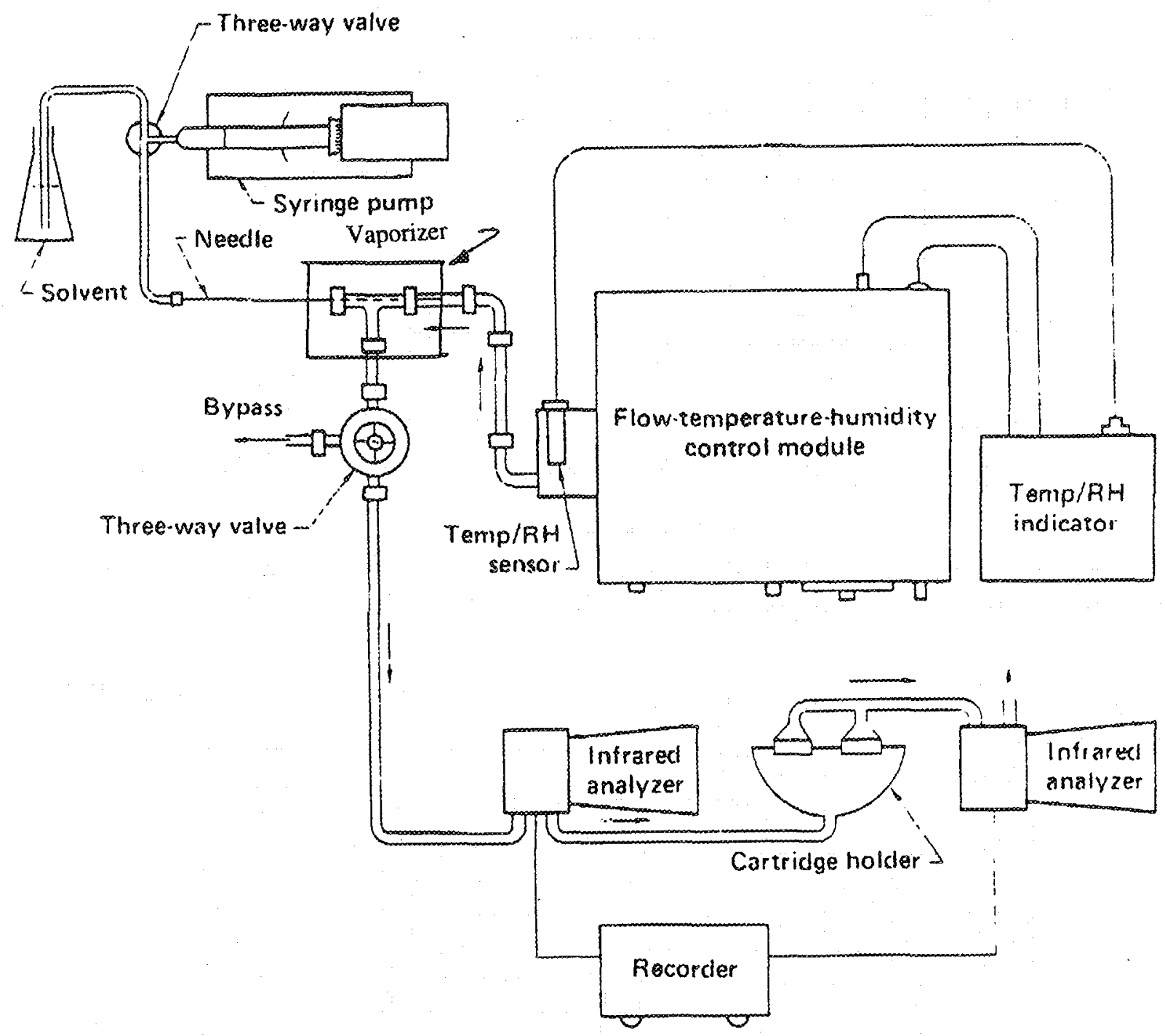

Figure 2. Schematic diagram of the experimental apparatus used in the smallscale carbon tests. 
Figure 3 shows the DMSO removal efficiency for each of the eight carbon canisters as a function of exposure time. All of the carbons have similar DMSO adsorption properties. However, sample G215 from PICA USA Inc. (Columbus, OH) had a slightly better performance than the other samples and was therefore selected for the carbon filter in our project. The carbon weight, adsorbed DMSO weight, and the pressure drop for each of the canisters is shown in Table 1.

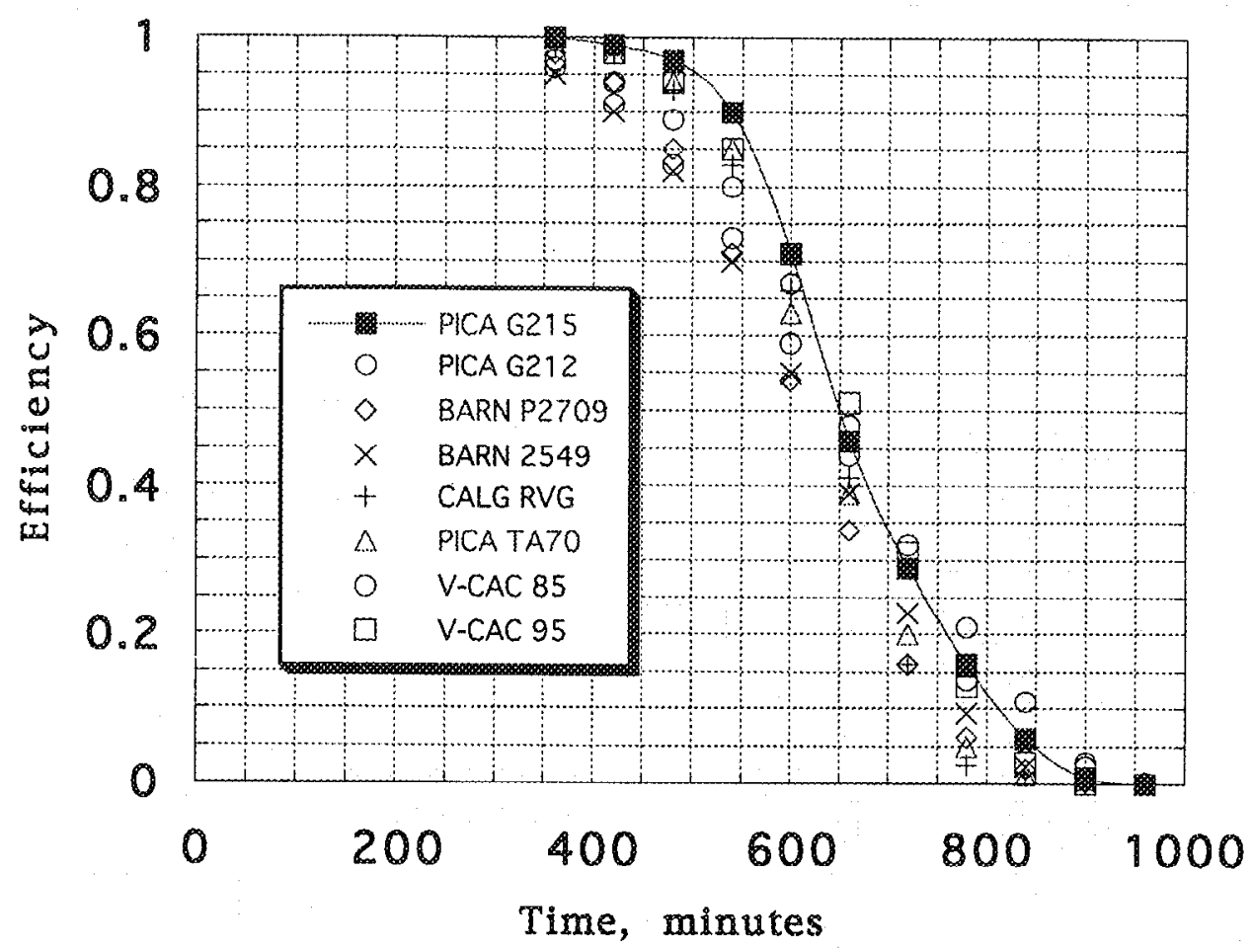

Figure 3. Survey of carbon capacities plotted as efficiency versus exposure time at $6 \mathrm{~m} / \mathrm{min}$ flow velocity and $500 \mathrm{ppm}(1.59 \mathrm{~g} / \mathrm{m} 3)$ DMSO.

Table 1. Experimental measurements of carbon cartridge samples in screening tests at $6 \mathrm{~m} / \mathrm{min}$.

\begin{tabular}{|l|l|l|l|}
\hline Sample & $\begin{array}{l}\text { Carbon } \\
\text { Weight, g }\end{array}$ & $\begin{array}{l}\text { DMSO } \\
\text { Adsorbed, g }\end{array}$ & $\begin{array}{l}\text { Pressure } \\
\text { Drop, in. H2O }\end{array}$ \\
\hline PICA G215 & 45.9 & 31.6 & 0.31 \\
\hline PICA G212 & 42.6 & 31.3 & 0.21 \\
\hline BARN P2709 & 55.2 & 29.7 & 0.27 \\
\hline BARN 2549 & 47.7 & 30.4 & 0.20 \\
\hline CALG RVG & 51.7 & 30.9 & 9.31 \\
\hline PICA TA70 & 51.1 & 30.6 & 0.30 \\
\hline V-CAC 85 & 44.3 & 31.9 & 0.29 \\
\hline V-CAC 95 & 45.8 & 32.5 & 0.31 \\
\hline
\end{tabular}

We then conducted additional tests on new cartridges of PICA G215 at 14.7 and $43.9 \mathrm{l} / \mathrm{min}$ flow rates, which correspond to flow velocities of 3 and $12 \mathrm{~m} / \mathrm{min}$. These tests were needed to establish the adsorption parameters for the design of 
the carbon filter. Figure 4 shows the results of the three carbon canisters of PICA G215 tested at 3, 6 and $12 \mathrm{~m} / \mathrm{min}$ flow velocity. We see that the faster flows results in shorter saturation times. The experimental measurements of the PICA G215 carbon samples are shown in Table 2.

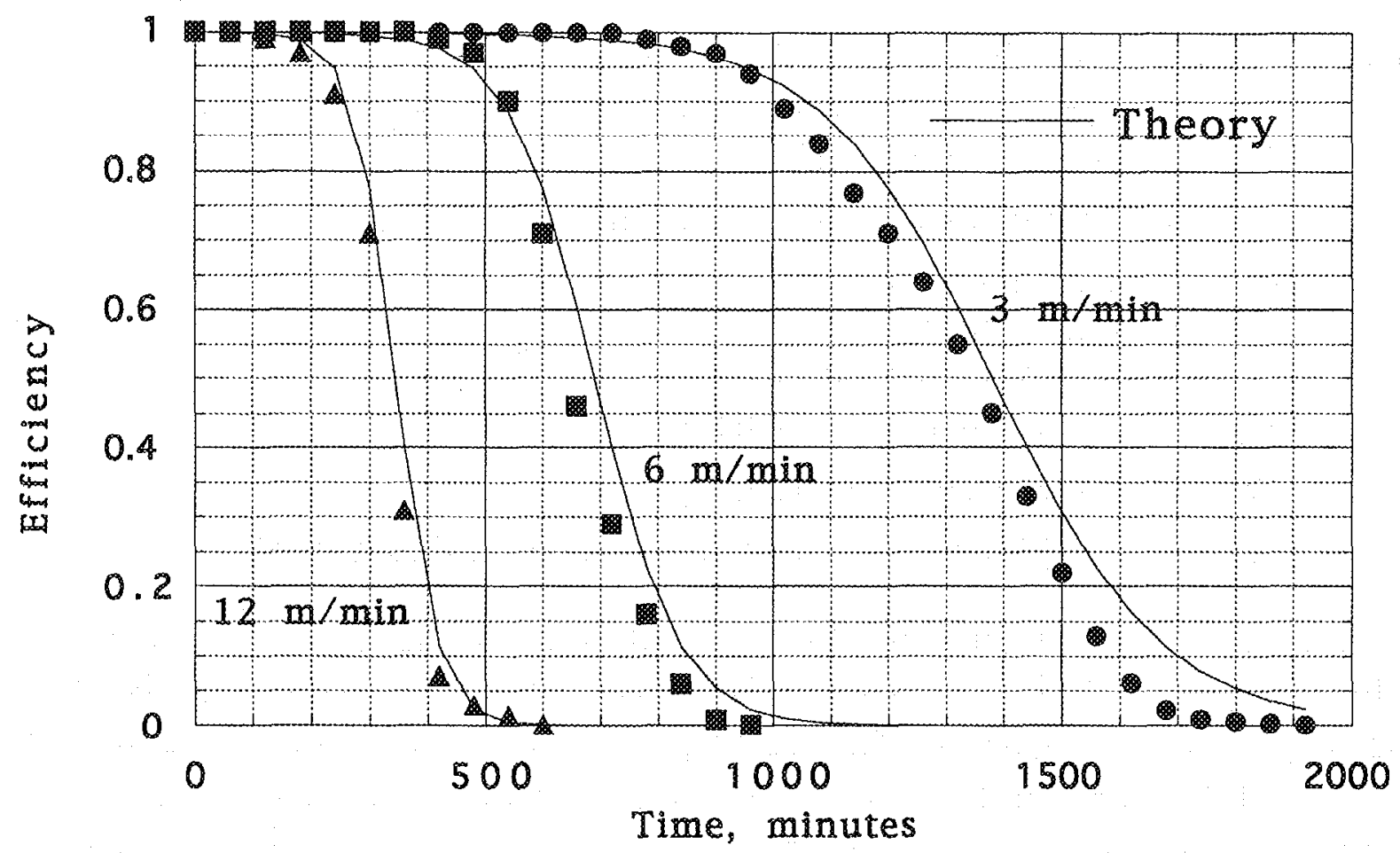

Figure 4. Efficiency of PICA G215 canisters at 3,6 and $12 \mathrm{~m} / \mathrm{min}$ flow velocity. Points are experimental data; solid lines represent theory.

Table 2. Experimental measurements of PICA G215 carbon samples in tests at 3,6 and $12 \mathrm{~m} / \mathrm{min}$.

\begin{tabular}{|c|c|c|c|c|c|c|}
\hline $\begin{array}{l}\text { Velocity } \\
\mathrm{V} \\
\mathrm{m} / \mathrm{min}\end{array}$ & $\begin{array}{l}\text { Flow rate, } \\
1 / \text { min }\end{array}$ & $\begin{array}{l}\text { Pressure } \\
\text { drop } \\
\text { in. } \mathrm{H}_{2} \mathrm{O}\end{array}$ & $\begin{array}{l}\text { Carbon } \\
\text { Wt } \\
W_{c}, g\end{array}$ & $\begin{array}{l}\text { DMSO } \\
\text { Wt } \\
W_{a}, g\end{array}$ & $\begin{array}{l}\text { Saturated } \\
\text { Capacity } \\
W_{S}=W_{a} / W_{C}\end{array}$ & $\begin{array}{l}\text { Carbon bulk } \\
\text { density, } \rho_{C} \\
g / 1\end{array}$ \\
\hline 3 & 14.7 & 0.13 & 44.0 & 32.8 & 0.745 & 393 \\
\hline 6 & 29.4 & 0.31 & 45.9 & 31.6 & 0.688 & 410 \\
\hline 12 & 58.8 & 0.57 & 43.9 & 32.5 & 0.740 & 392 \\
\hline
\end{tabular}

In order to design an activated carbon filter for removing DMSO vapor, it was first necessary to determine the adsorption capacity of the selected carbon for DMSO, $W_{\mathrm{s}}$, and the coefficient, $\mathrm{K}_{\mathrm{v}}$, for the rate of adsorption. Once these two parameters are determined, theoretical equations can be used to determine the key design parameters for the gas filter. The dynamic adsorption capacity, $W_{\mathrm{s}}$, was experimentally determined and is shown in Table 2. The kinetic coefficient, $\mathrm{K}_{\mathrm{v}}$. characterizing the rate of adsorption is derived from matching experimental 
data with a theoretical model. We used the modified Wheeler equation, shown in Equation 1 to derive the kinetic coefficient. ${ }^{(2)}$

$t=W_{s} W_{c} /(C A V)+W_{s} \rho_{c} /\left(C K_{v}\right) \ln [(1-E) / E]$

where $A=$ cartridge area, $4.91 / \mathrm{m}\left(49 \mathrm{~cm}^{2}\right)$

$\mathrm{C}=$ DMSO concentration, $1.59 \times 10^{-3} \mathrm{~g} / 1(500 \mathrm{ppm})$

$\mathrm{E}=$ DMSO removal efficiency

$\mathrm{K}_{\mathrm{V}}=$ kinetic adsorption coefficient, min..$^{-1}$

$\rho_{\mathrm{C}}=$ carbon bulk density, $\mathrm{g} / 1$

$\mathfrak{t}=$ time, minutes

$\mathrm{V}=$ flow velocity, $\mathrm{m} / \mathrm{min}$.

$\mathrm{W}_{\mathrm{c}}=$ carbon weight in cartridge, $\mathrm{g}$

$\mathrm{W}_{\mathrm{a}}=$ DMSO weight adsorbed, $\mathrm{g}$

$\mathrm{W}_{\mathrm{S}}=$ DMSO saturated capacity $=\mathrm{W}_{\mathrm{a}} / \mathrm{W}_{\mathrm{c}}$, dimensionless

Values of $\mathrm{K}_{\mathrm{v}}$ were determined by substituting the parameter values from Table 2 into Equation 1 and fitting each of the three equations to the corresponding efficiency curves in Figure 4. The least squares fits produced $K_{V}$ values of 1369 , 2750 and $4801 \mathrm{~min}^{-1}$ at 3,6 and $12 \mathrm{~m} / \mathrm{min}$ flow velocities respectively. To establish the velocity dependence of $\mathrm{K}_{\mathrm{V}}$, we plotted the values of $\mathrm{K}_{\mathrm{v}}$ versus the flow velocity in Figure 5.

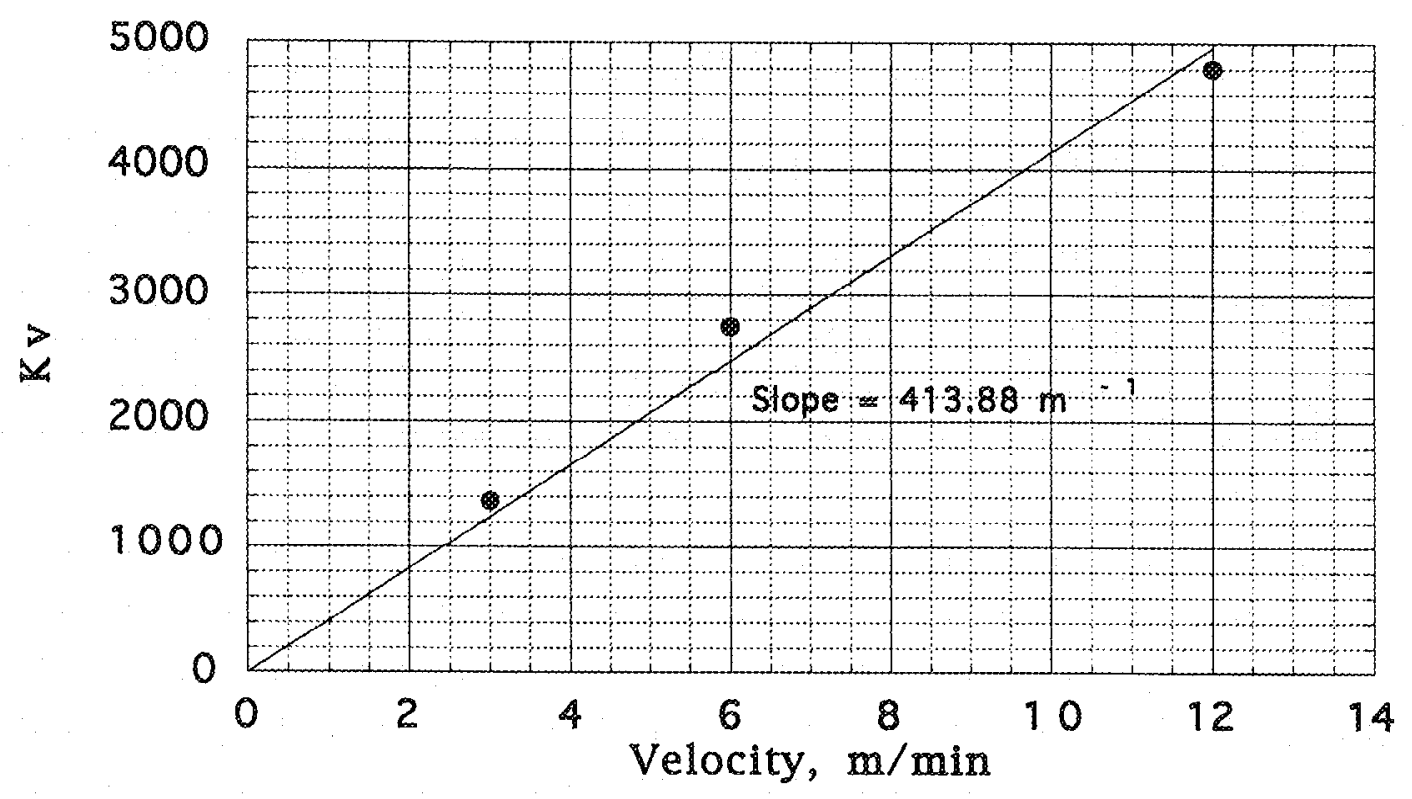

Figure 5 Determination of $\mathrm{K}_{\mathrm{v}}$ dependence on velocity. 
From Figure 5, we have

$K_{v}=k_{v} V=413.88 \mathrm{~V} \min ^{-1} \quad(R=0.99035)$

where the slope, $k_{v}$, equals $413.88 \mathrm{~m}^{-1}$. Substituting this expression into Equation 1 yields,

$\imath=W_{s} W_{C} /(C A V)+W_{s} \rho_{C} /\left(C k_{v} V\right) \ln [(1-E) / E]$

All of the constants in Equation 3 can be lumped together into constants $c_{1}$ and $c_{2}$ to yield.

$t=c_{1} / V+\left(c_{2} / V\right) \ln [(1-E) / E]$

Replacing the constants in Equation 4 with the values in Table 2 yields $c_{1}=$ $4207.4,4053$ and 4169.7 and $c_{2}=444.6,427.7$ and 439.7 for $V=3,6$ and 12 $\mathrm{m} / \mathrm{min}$ respectively. Averaging these constant values yields

$t=4143.4 / V+(437.3 / V) \ln [(1-E) / E]$

Equation 5 was used to generate the theoretical curves in Figure 4.

The increasing deviation in Figure 4 between the experimental data and theory at slower velocities is most likely due to the assumption of irreversible adsorption. In practice, the adsorbed DMSO will not be adsorbed irreversibly and will be released, which is more pronounced at longer times and at higher carbon saturation values.

\section{Design of Full-scale Carbon Filter}

We used Equation 5 and the parameter values determined in the cartridge studies to design the carbon filter for use in the W79 HE Dissolution Workstation. A major constraint on the filter design is the thickness of the carbon bed. Although we used a bed depth of $2.3 \mathrm{~cm}(0.91 \mathrm{inch})$ in our screening tests, existing standards on carbon filters require a minimum of 2 inches ${ }^{(3,4)}$. This minimum bed depth was established to avoid channeling effects in the ventilation filters. However, since the pressure drop across the filter is directly proportional to the bed depth, it is desirable to minimize the bed depth. Thus, the optimum bed depth that satisfies the current standards and minimizes the pressure drop is 2 inches. To include the effect of carbon bed depth in Equation 3, we made the following two substitutions: 
$Q=A V$

$\rho_{\mathrm{c}}=\mathrm{W}_{\mathrm{c}} / \mathrm{AT}$

where, $\quad Q=$ flow rate, $1 /$ min.

$\mathrm{T}=$ carbon bed thickness, $\mathrm{m}$

Substituting Equations 6 and 7 into Equation 3 and rearranging yields,

$l=W_{s} W_{c} /(C Q)\left[1+\left(1 / k_{v} T\right) \ln [(1-E) / E]\right.$

Equation 8 can be used to establish how much carbon, $W_{c}$, should be used for a given exhaust flow rate, $\mathrm{Q}$, and concentration of DMSO, $\mathrm{C}$ and for a desired filter life, t. However since the DMSO concentration and exhaust flow rate vary considerably during a typical dissolution operation, it is more efficient to size the carbon filter based on the estimated total mass of DMSO vapor from the dissolution and clean-up. The total mass, M, of DMSO vapor exhausted from the Workstation for a single $\mathrm{HE}$ assembly is computed from the following equation:

$M=\sum_{\operatorname{lod}} n_{\dot{1}} C_{\dot{1}} Q_{i} t_{i}$

where $\quad i=$ the $i$ th phase of the dissolution operation.

$\mathrm{n}_{\mathfrak{i}}=$ the number of cycles for a given operation.

Substituting Equation 9 into Equation 8 yields

$N=\left(W_{S} W_{c} / M\right)\left[1+\left(1 / k_{v} T\right) \ln [(1-E) / E]\right.$

where $\quad \mathrm{N}=$ number of $\mathrm{HE}$ assembles that can be cleaned before replacing the carbon filter.

Substituting the values $E=0.9, k_{v}=413.9 \mathrm{~m}^{-1}, T=0.0508 \mathrm{~m}$, we have

$N=\left(W_{s} W_{c} / M\right)(0.896)$

We can estimate the mass of DMSO vapor, $M$, entering the carbon filter from Equation 9 for the different stages of the dissolution operation. We estimated the DMSO vapor concentration, $C_{i}$, from the equilibrium vapor concentration versus temperature in Figure $6^{(5)}$. The corresponding temperature is measured after the demister pad in the Workstation exhaust system. The temperatures during the 
dissolution operation were experimentally determined in early tests at LLNL. The temperatures for the rinse operations are estimates. The exhaust flow is experimentally determined to be about $1 \mathrm{cfm}$ (due to leaks) during the nonvented operations and $35 \mathrm{cfm}$ in the vent mode when the inlet valve is open. The measured times also represent early tests at Pantex. However, since LLNL tests showed the Workstation aerosol concentration was reduced to nearly 0 after 2 minutes with a $20 \mathrm{cfm}$ flow, we estimate the Workstation will be purged within 1 minute at $35 \mathrm{cfm}$. In addition, we used one half of the peak vapor concentration to represent the average during this period. All of the values for $C_{i}, Q_{i}, t_{i}$, and $\mathrm{n}_{\mathrm{i}}$ are shown in Table 3 . From Table 3 we have $\mathrm{M}=42.3 \mathrm{~g}$.

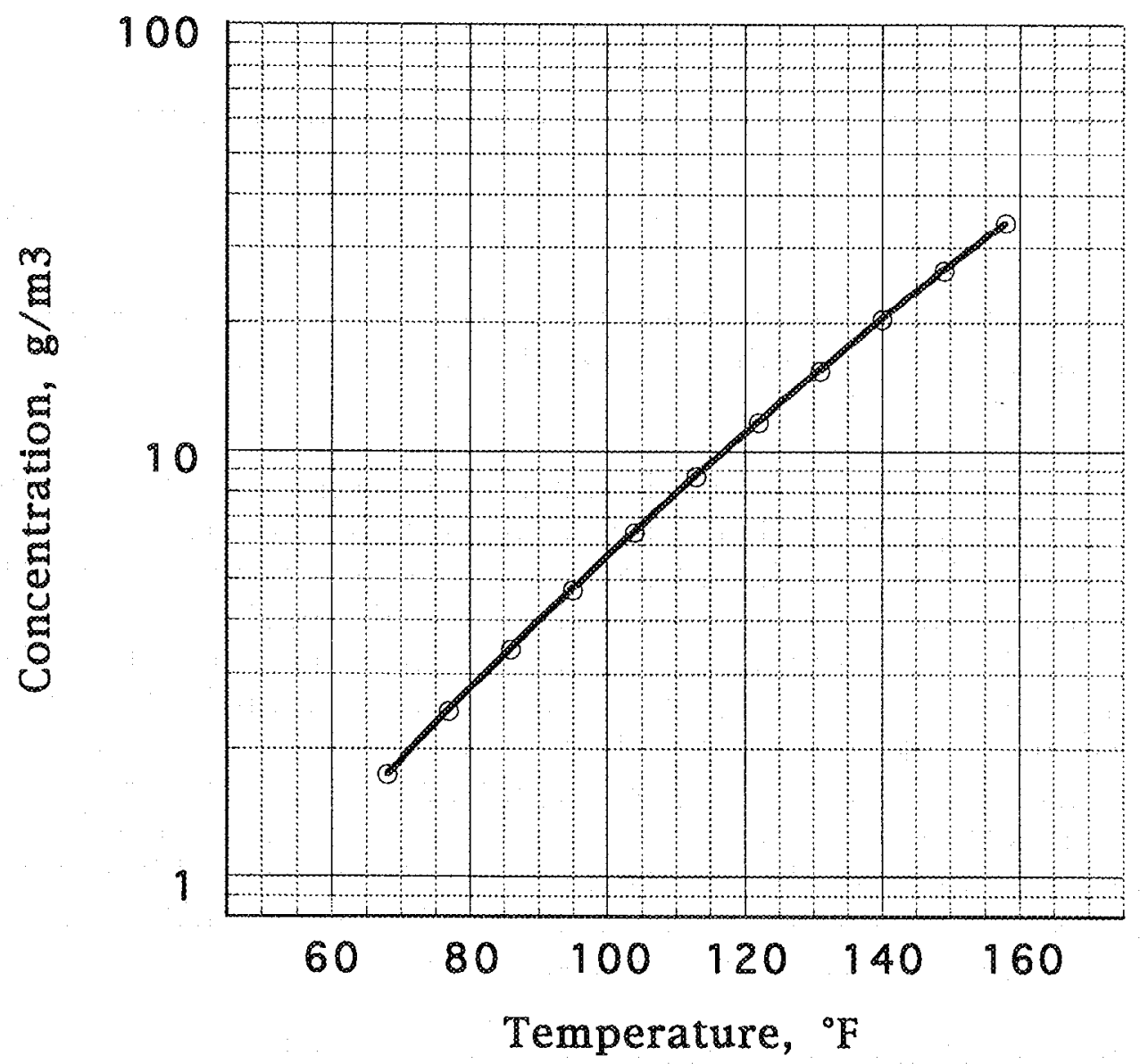

Figure 6. Mass concentration of DMSO vapor corresponding as a function of temperature $^{(5)}$. 
Table 3. Determination of DMSO vapor from Equation 9.

\begin{tabular}{|l|l|l|l|l|l|l|}
\hline Operation & $\begin{array}{l}\text { Temp } \\
{ }^{\circ} \mathrm{F}\end{array}$ & $\begin{array}{l}\text { DMSO } \\
\text { Conc. } \\
\left(\mathrm{C}_{\mathrm{i}}\right) \\
\mathrm{g} / \mathrm{m} 3\end{array}$ & $\begin{array}{l}\text { Exhaust } \\
\text { flow, } \\
\left(\mathrm{Q}_{\mathrm{j}}\right) \\
\mathrm{cfm}\end{array}$ & $\begin{array}{l}\text { Time } \\
\left(\mathrm{t}_{\mathrm{i}}\right) \\
\text { Min. }\end{array}$ & $\begin{array}{l}\text { Number } \\
\text { of cycles } \\
\mathrm{n}_{\mathrm{i}}\end{array}$ & $\begin{array}{l}\text { DMSO } \\
\text { mass, } \\
\left(\mathrm{m}_{\mathrm{j}}\right) \\
\mathrm{g}\end{array}$ \\
\hline Dissolution/spray & 65 & 1.5 & 1 & 360 & 1 & 15.3 \\
\hline Dissolution/vent & 60 & 0.6 & 35 & 60 & 24 & 14.3 \\
\hline $\begin{array}{l}\text { Rinse/ } \\
\text { SprayManifold }\end{array}$ & 60 & 1.2 & 1 & 120 & 1 & 4.1 \\
\hline Rinse/Workstation & 65 & 1.5 & 1 & 30 & 1 & 1.3 \\
\hline Rinse/Vent & 60 & 0.6 & 35 & 1 & 5 & 3.0 \\
\hline Condensor/rinse & 90 & 4.0 & 1 & 30 & 1 & 3.4 \\
\hline Condenser/vent & 70 & 0.9 & 35 & 1 & 1 & 0.9 \\
\hline
\end{tabular}

Substituting the values $M=42.3 \mathrm{~g}$ and $W_{s}=0.724$ into Equation 11 yields,

$\mathrm{N}=0.0153 \mathrm{~W}_{\mathrm{C}}$

Equation 12 shows the number of $\mathrm{HE}$ assemblies increases in direct proportion to the mass of carbon in the carbon filter. Each $\mathrm{HE}$ assembly requires $65.3 \mathrm{~g}$ of carbon.

Packaging the carbon into a filter element was constrained to having a 2 inch thick bed to minimize the pressure drop and minimizing the overall size while providing at least one month of continuous operation. We selected the cylindrical cartridge design because of the ease of fabrication and refilling the carbon. The final dimensions selected were 6 and 10 inches inside and outside diameters and 12 inches high. This unit has a volume of 9.881 and can accommodate $3930 \mathrm{~g}$ of carbon. Based on Equation 14, this carbon filter can be used to process about 60 HE assemblies (Equation 12 shows 59.7) before replacing the carbon. We should note that more accurate estimates of carbon life could be obtained with improved input data in Table 3. Alternatively, the efficiency of the carbon filter can be measured experimentally at increasing loadings to establish the actual number of HE assemblies that can be processed prior to carbon replacement.

The schematic of the cylindrical cartridge filter that we designed is shown in Figure 7 , where the cartridge is shown mounted inside a cylindrical housing. The exhaust flows from the bottom port into the interior of the carbon filter, passes through the 2 inch bed and exits around the exterior of the cartridge and finally through the top port. The carbon bed is a 2-inch thick concentric cylinder contained between concentric cylinders made of perforated metal screens that are 12 inches long and have 10 and 6 -inch diameters. The net carbon volume of this 
filter is $9.88 \mathrm{l}$. Figures $8-10$ show the partially assembled canister, the fully assembled canister, and the exhaust system housing for the canister.

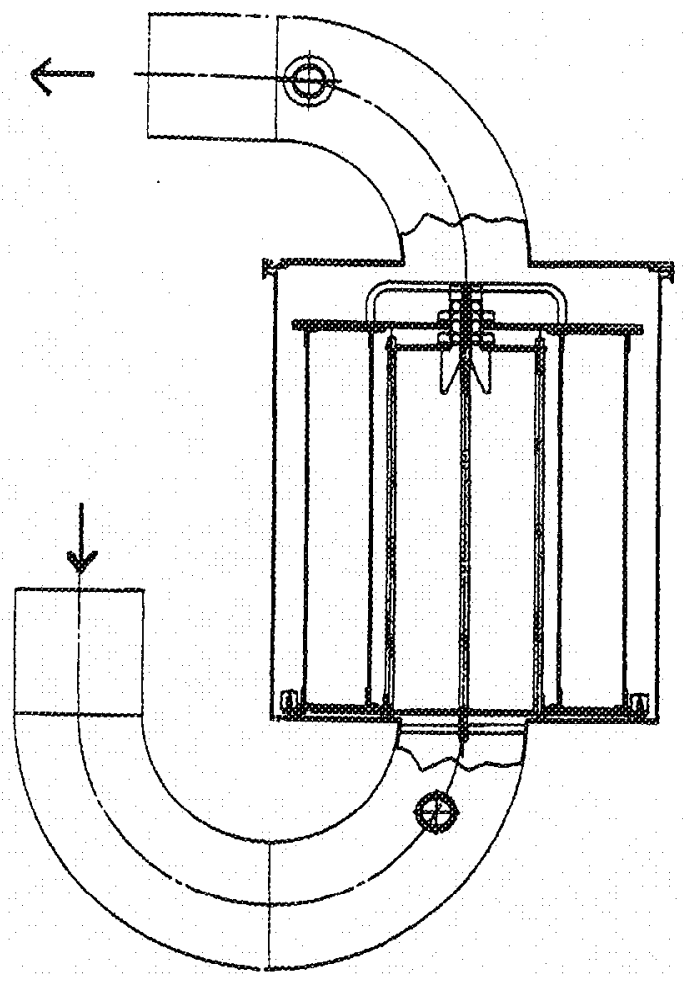

Figure 7. Schematic of cylindrical carbon filter cartridge mounted in a housing.

To prevent the possibility of DMSO condensing and collecting inside the carbon filter, we directed the exhaust through a U-tube section before entering the carbon filter. Any DMSO condensate would collect at the low point of the U-tube and can be drained through a plug. It is possible to form DMSO condensate in the lines when the ambient laboratory temperature is lower than the exit temperature of the demister. This may occur when rinsing out the condenser because hot DMSO liquid is sprayed on the condenser tubes from above. Hot DMSO vapor will therefore pass into the exhaust system without cooling in the heat exchanger. As the heated DMSO vapor cools, it will condense in the exhaust lines and filters.

We measured the efficiency of the carbon filter during a practice dissolution operation and showed the carbon filter was only about $70 \%$ efficient. We measured the DMSO concentration before and after the filter with a Boxborough infrared analyzer. Since the predicted efficiency should be in excess of $99 \%$, we suspected the poor performance was due to the carbon loading procedure that we used. We filled the annular space with carbon by pouring the carbon granules directly from a container and then shaking the filter unit to insure tight packing. This test demonstrated the importance of using the established carbon filling procedure where carbon granules are poured through multiple screens to insure a well packed bed. 


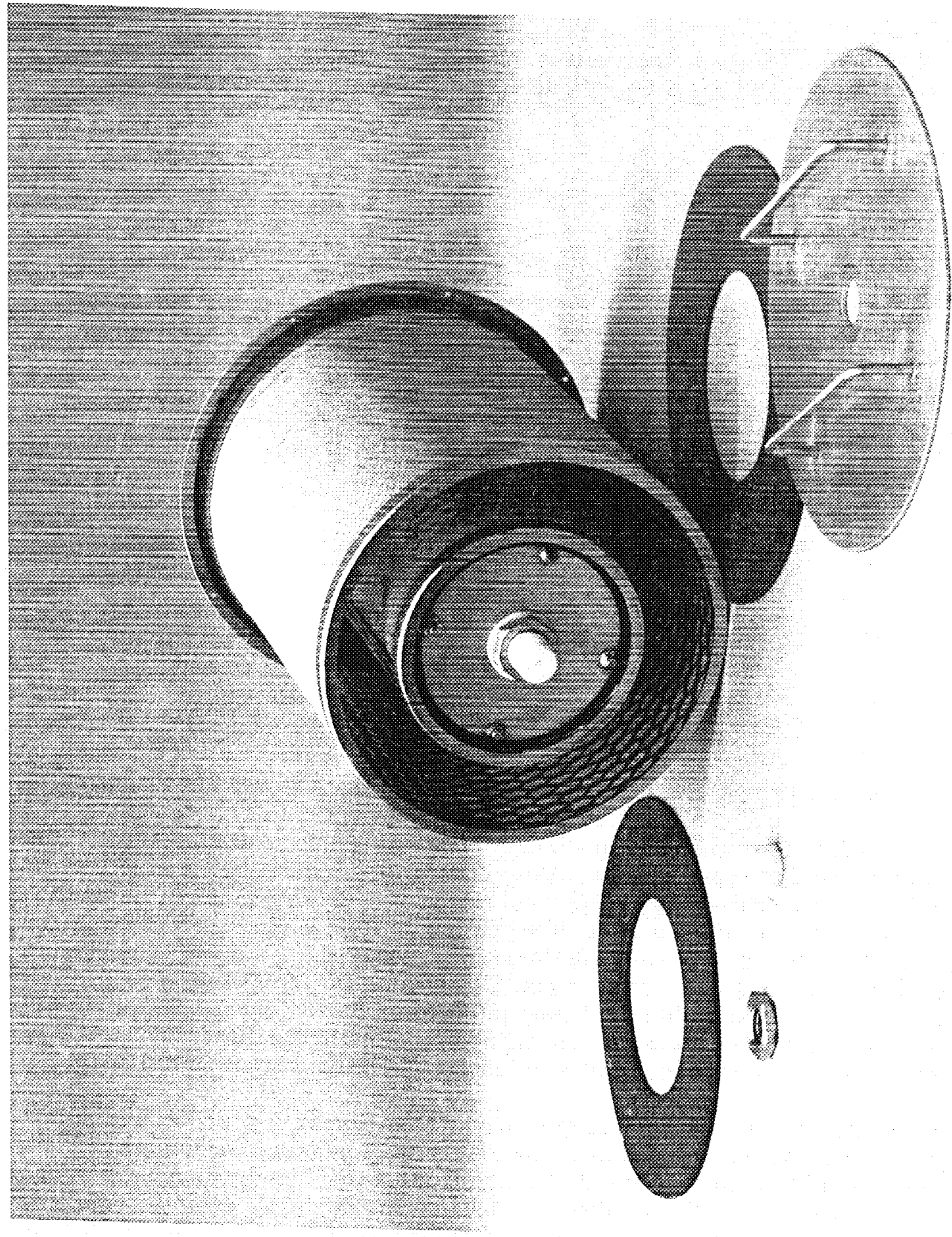

Figure 8. Photograph of the cylindrical filter canister partially disassembled showing the annular space for holding the granular carbon. The view is from the topside. 


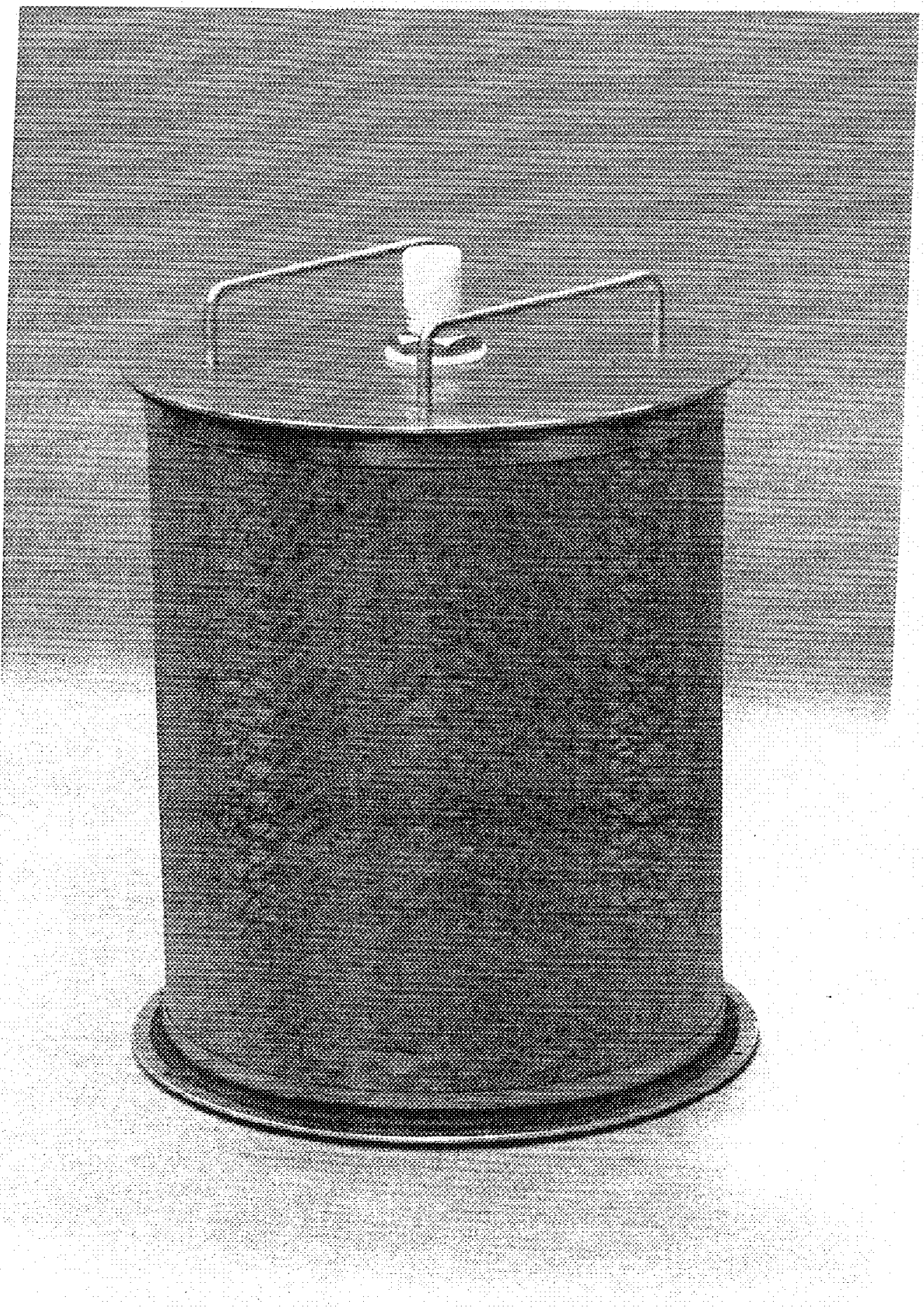

Figure 9. Photograph of the assembled carbon filter canister. 


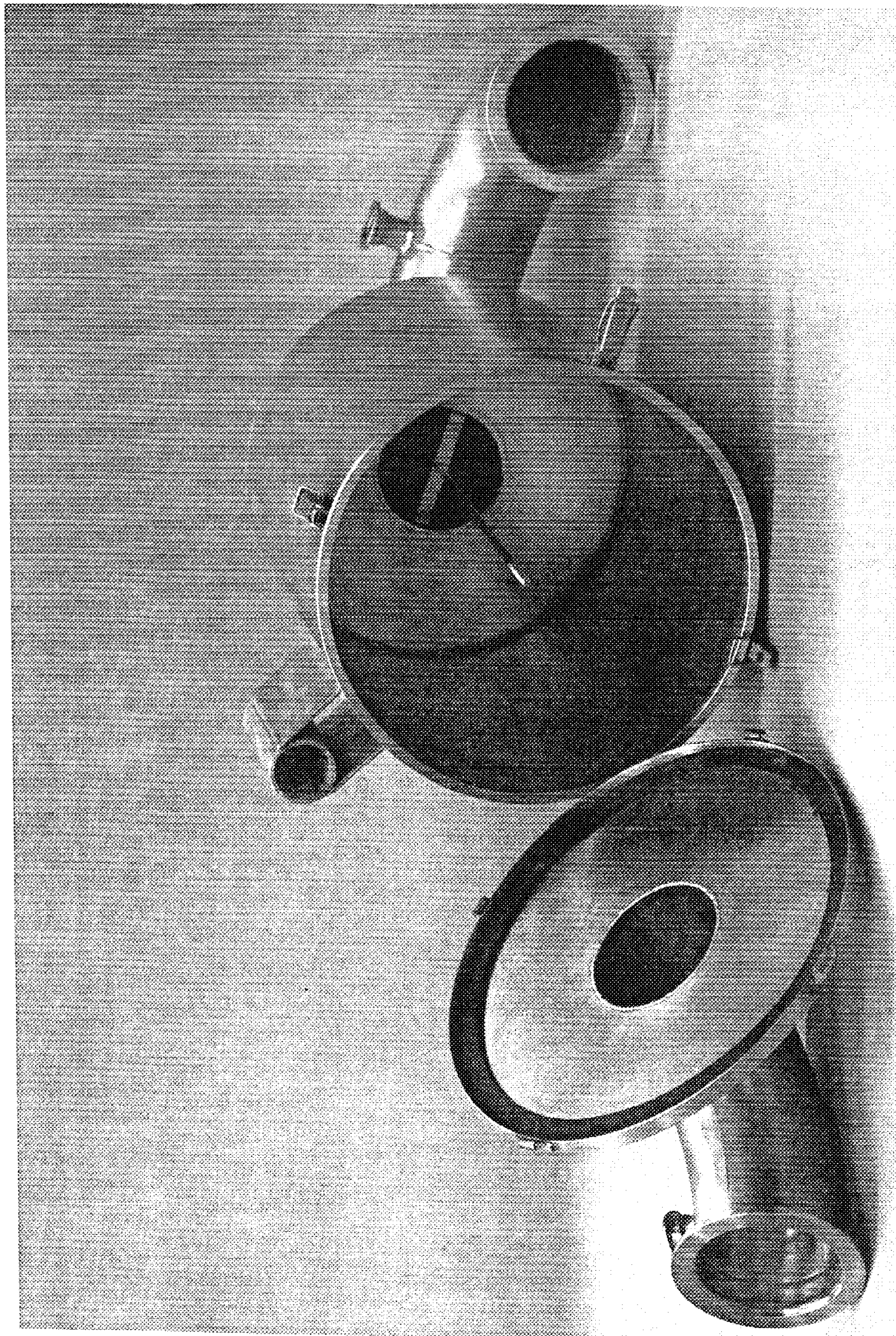

Figure 10. Photograph of the exhaust system housing for the carbon canister. 


\section{Eilling Canister With Carbon Granules}

We designed and built a filling tube, shown in Figure 11, to be used when filling the carbon canister with carbon granules. The filling tube has an inlet nozzle and two stages of four screens with $1 / 4$ " $\times 1 / 4$ " openings. The screens act to disperse the carbon granules in a uniform distribution across the area independent of the initial point of entry where the carbon is poured. The first set of screens functions to disperse the carbon granules across the 2-inch inlet tube so the carbon is dispersed uniformly in a radial position by the cone. The second set of screens functions to disperse the carbon granules uniformly within the annular space of the carbon canister. Note the carbon filling tube fits directly over the carbon canister in Figure 11.

The procedure for filling a fresh charge of carbon into the canister is illustrated in Figures 12-14. The first step is to open the top lid of the canister and remove the old carbon. The empty canister and filling tube are shown in Figure 12. The filling tube is then mounted over the canister as shown in Figure 13. Carbon granules are then poured into the inlet funnel as illustrated in Figure 14. Additional carbon is added until the annular space of the canister is filled slightly over the rim. After the canister is filled, the inlet tube is lifted off the canister, and the carbon deposits inspected to verify the deposits are uniform around the circumference and are slightly over the top surface. A rubber gasket is then placed over the annual space and the top plate fastened to the canister 


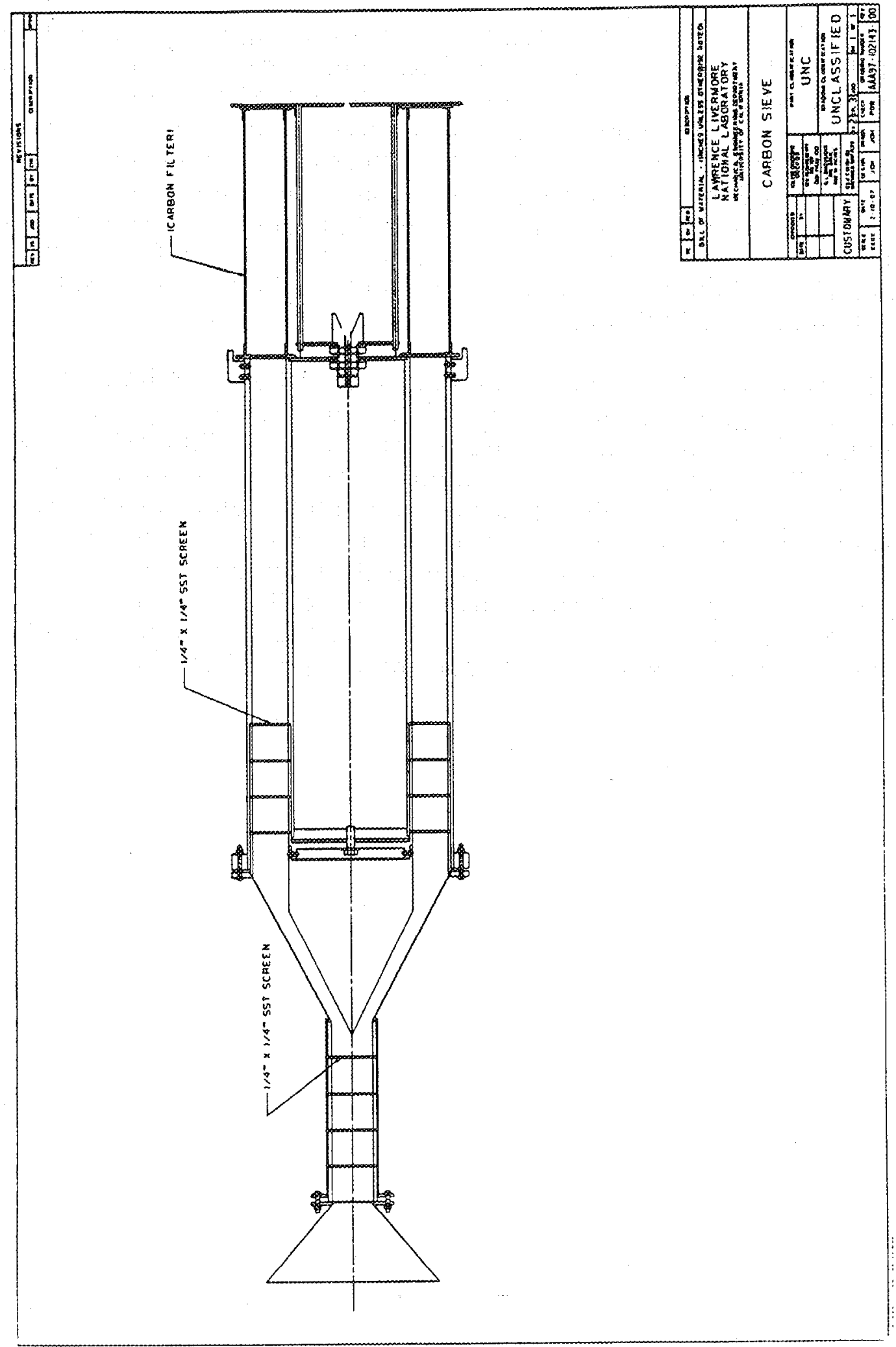

Figure 11. Schematic of carbon filling tube mounted over the carbon canister. 


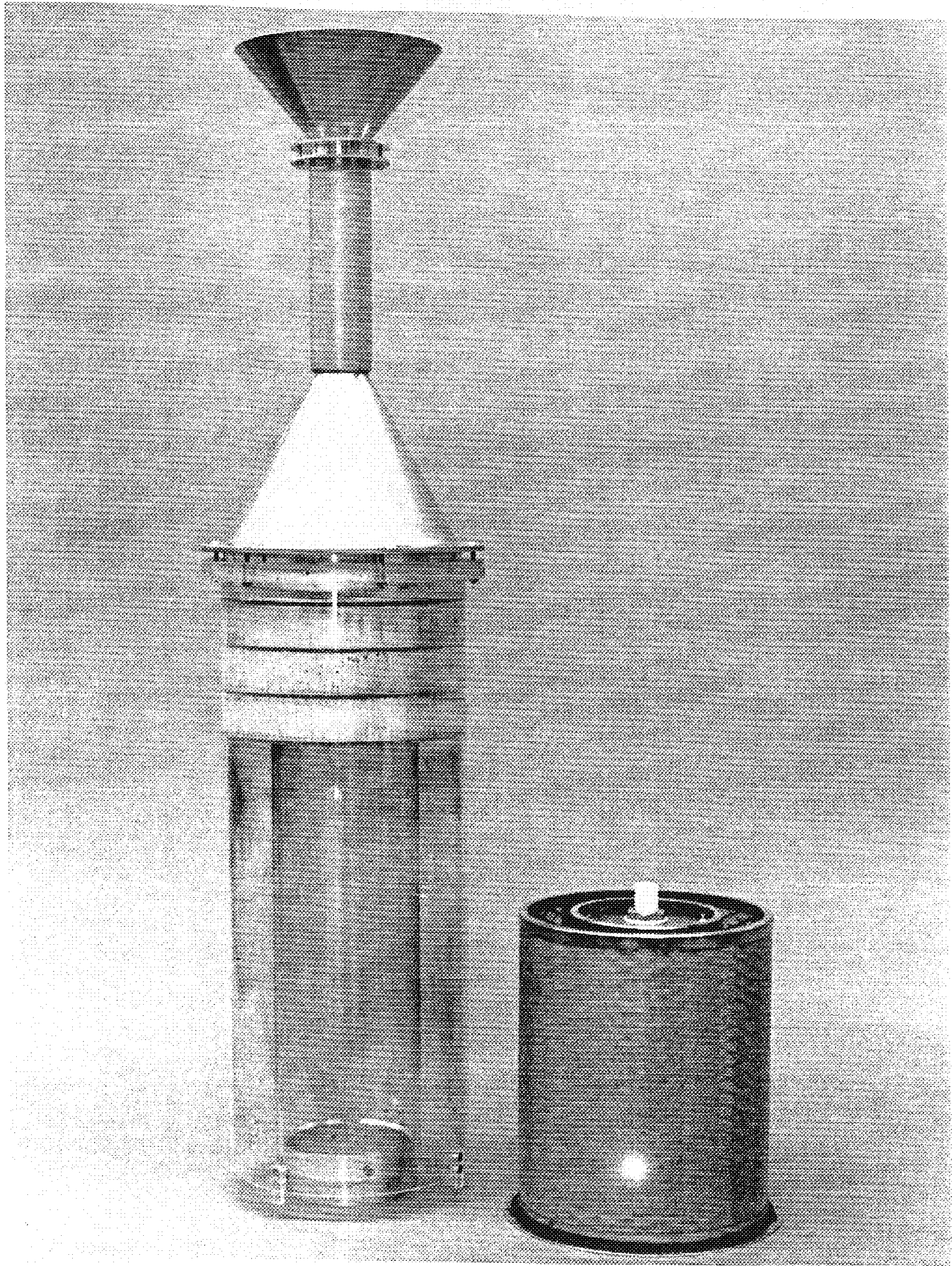

Figure 12. Photograph of the carbon filling tube and the empty carbon canister. 


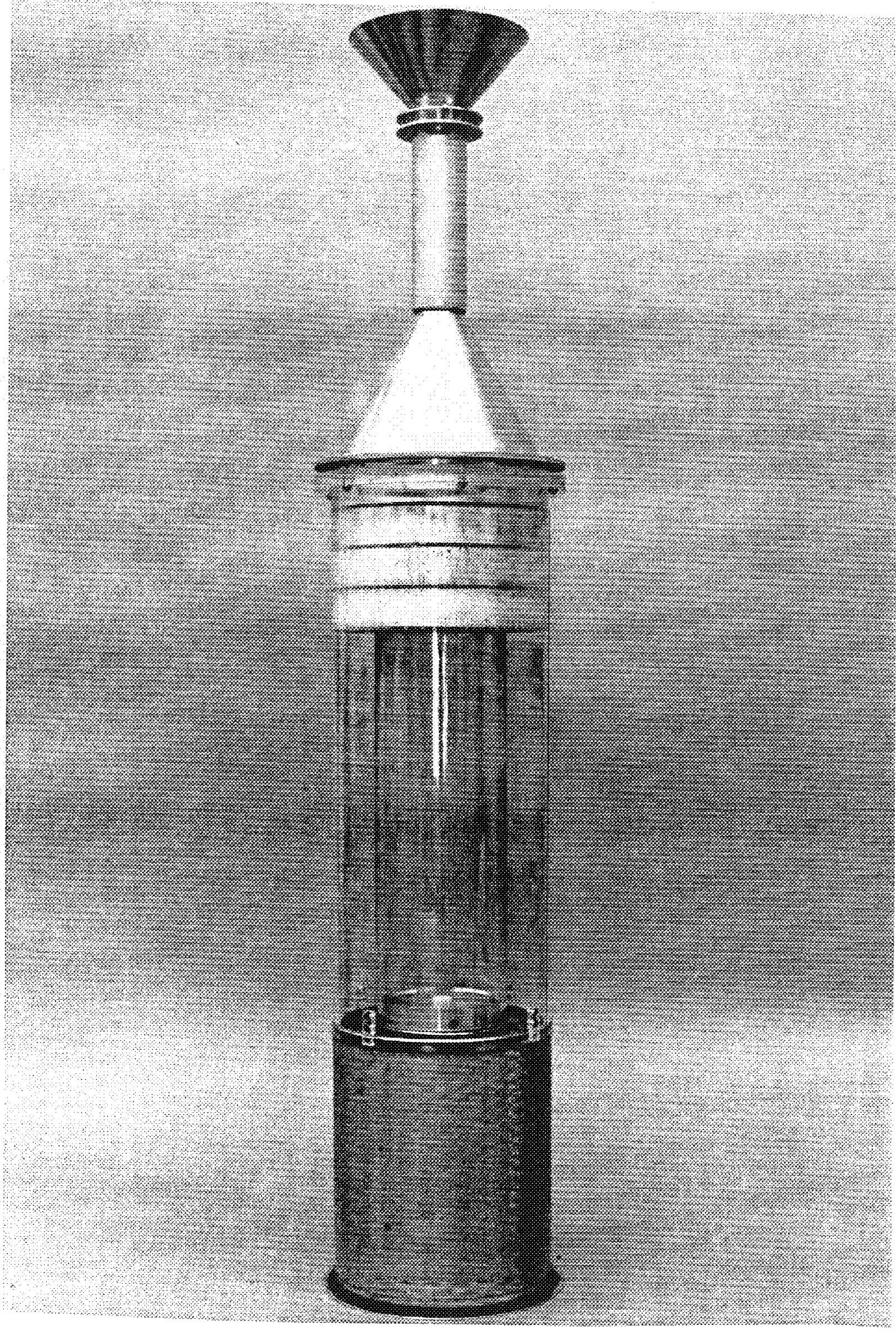

Figure 13. Photograph of the carbon filling tube mounted on the carbon canister. 


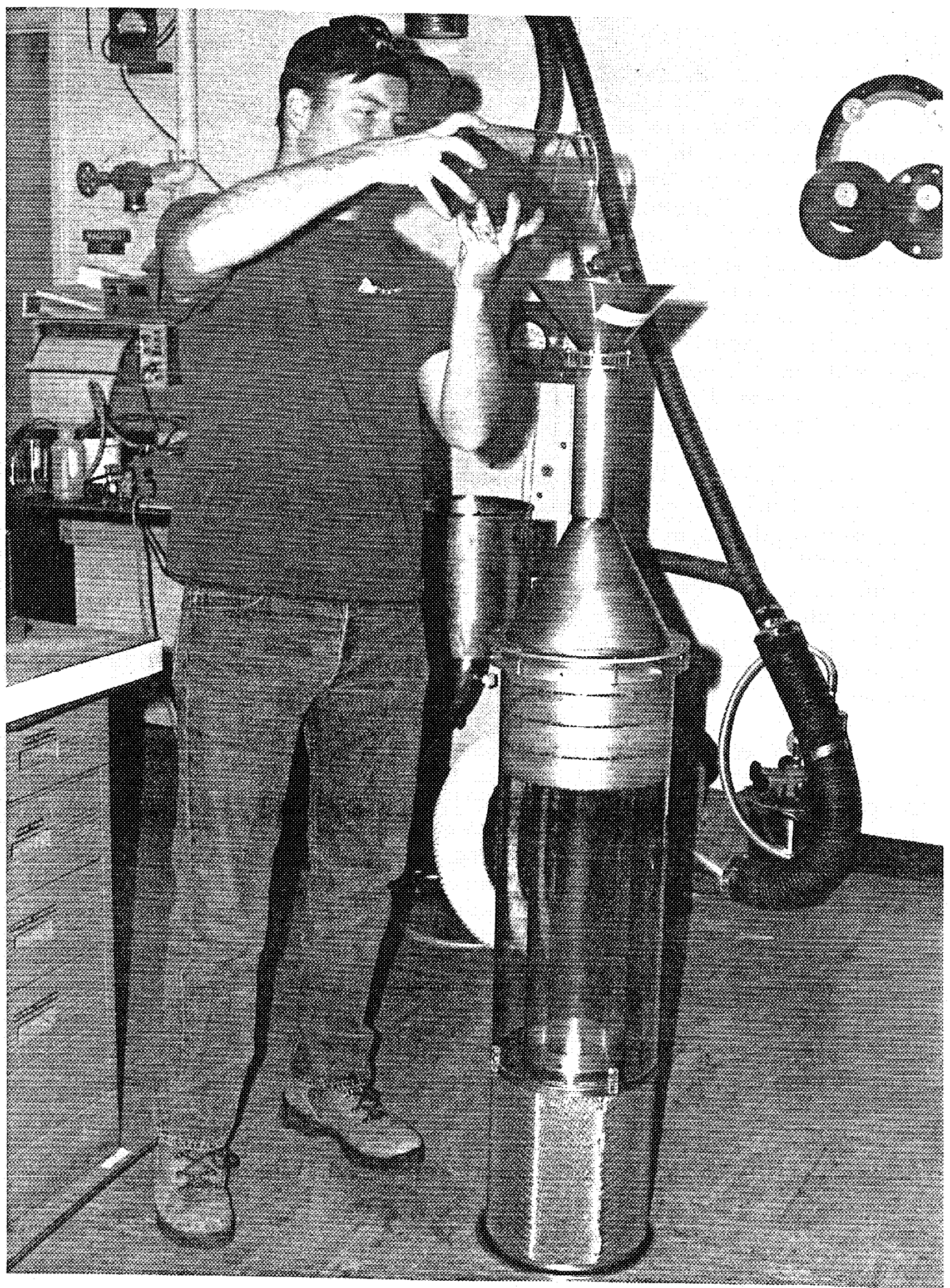

Figure 14. Photograph illustrating the use of the filling tube to fill the carbon canister with carbon . 


\section{Measurement of Carbon Canister Efficiency}

We measured the efficiency of the carbon canister mounted inside the exhaust system housing in a similar fashion as was done with the screening tests on small-scale tests. However, we measured only the efficiency of a fresh canister because of time limitations to conduct the full breakthrough curve as shown in Figure 4 for the small-scale filter. Using Equation 8, we estimate it would take about 40 hours of exposure to measure the breakthrough curve at the maximum room temperature exposure $(500 \mathrm{ppm}, 1.6 \mathrm{~g} / \mathrm{m} 3)$ and a flow rate of $35 \mathrm{cfm}$. Moreover, measuring the breakthrough curve for the carbon canister is not sufficient to establish the filter life in the W79 dissolution operation because of the variability in concentration, flow rate, and exposure time at each condition. The primary purpose of the efficiency test on the carbon canister is to demonstrate the efficacy of the carbon filling technique.

The schematic of the experimental apparatus used for measuring the efficiency of the carbon canister is shown in Figure 15. The apparatus is similar to that used for the small scale evaluations except no conditioned air supply is used to generate the $35 \mathrm{cfm}$. A syringe pump injects liquid DMSO into a $7 \mathrm{cfm}$, secondary air flow that is then directed into the $35 \mathrm{cfm}$ air flow passing through the carbon filter. Airflow is measured with a calibrated orifice, and the pressure drop across the carbon filter is measured with a Magnahelix gage. A Miran infrared analyzer is used to measure the DMSO concentration before and after the carbon filter.

The procedure for measuring the carbon efficiency consists of generating a known concentration of DMSO vapor in an air stream, passing the airflow through the carbon filter, and measuring the DMSO vapor concentration before and after the canister. Figure 16 shows the carbon canister with a fresh charge of carbon being inserted into the canister housing. Figure 17 shows a photograph of an operator measuring the efficiency of the carbon canister. The pressure drop across the carbon canister was 0.49 inches water at $35 \mathrm{cfm}$. At $35 \mathrm{cfm}$, the downstream concentration was less than $1 \mathrm{ppm}$ with an upstream concentration of $100 \mathrm{ppm}$, yielding an efficiency greater than $99 \%$. The test was repeated after removing the carbon canister and dropping it four times at a height of 2 inches to simulate rough handling. A small amount (50 grams) of carbon spilled from the canister. (The carbon loss was due to the retaining screen pulling loose from the bottom plate when the canister was dropped. This design defect was eliminated after the test by welding the retaining screen to the bottom plate.). Efficiency measurements after the drop test were the same as before. A final efficiency test was conducted at $4 \mathrm{cfm}$ and yielded the same concentration measurements and efficiency greater than $99 \%$. Thus, we concluded our carbon filling procedure was satisfactory and yields efficiency greater than $99 \%$. 


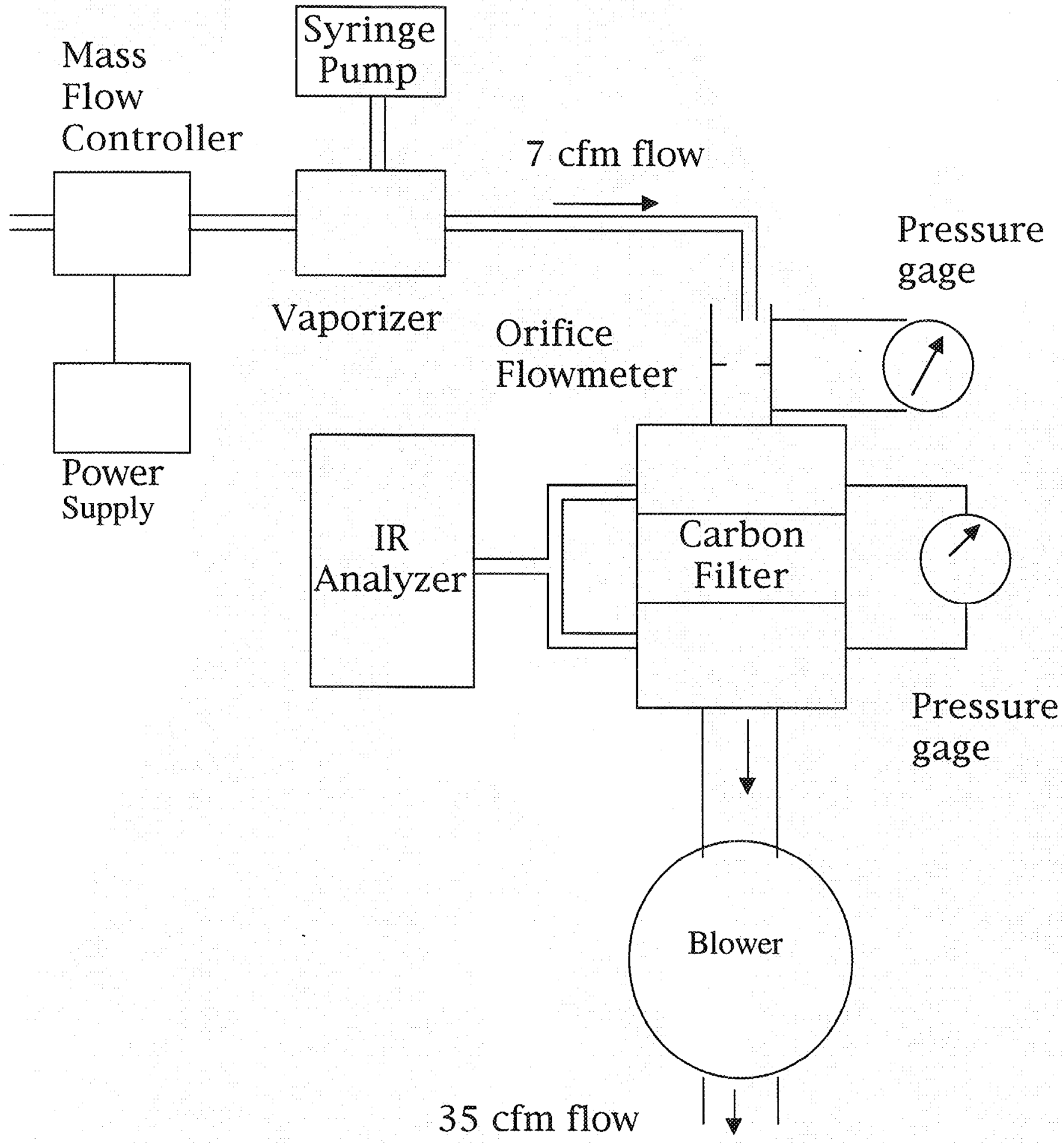

Figure 15. Schematic of the experimental apparatus for measuring the efficiency of the carbon canister in removing DMSO vapor. 


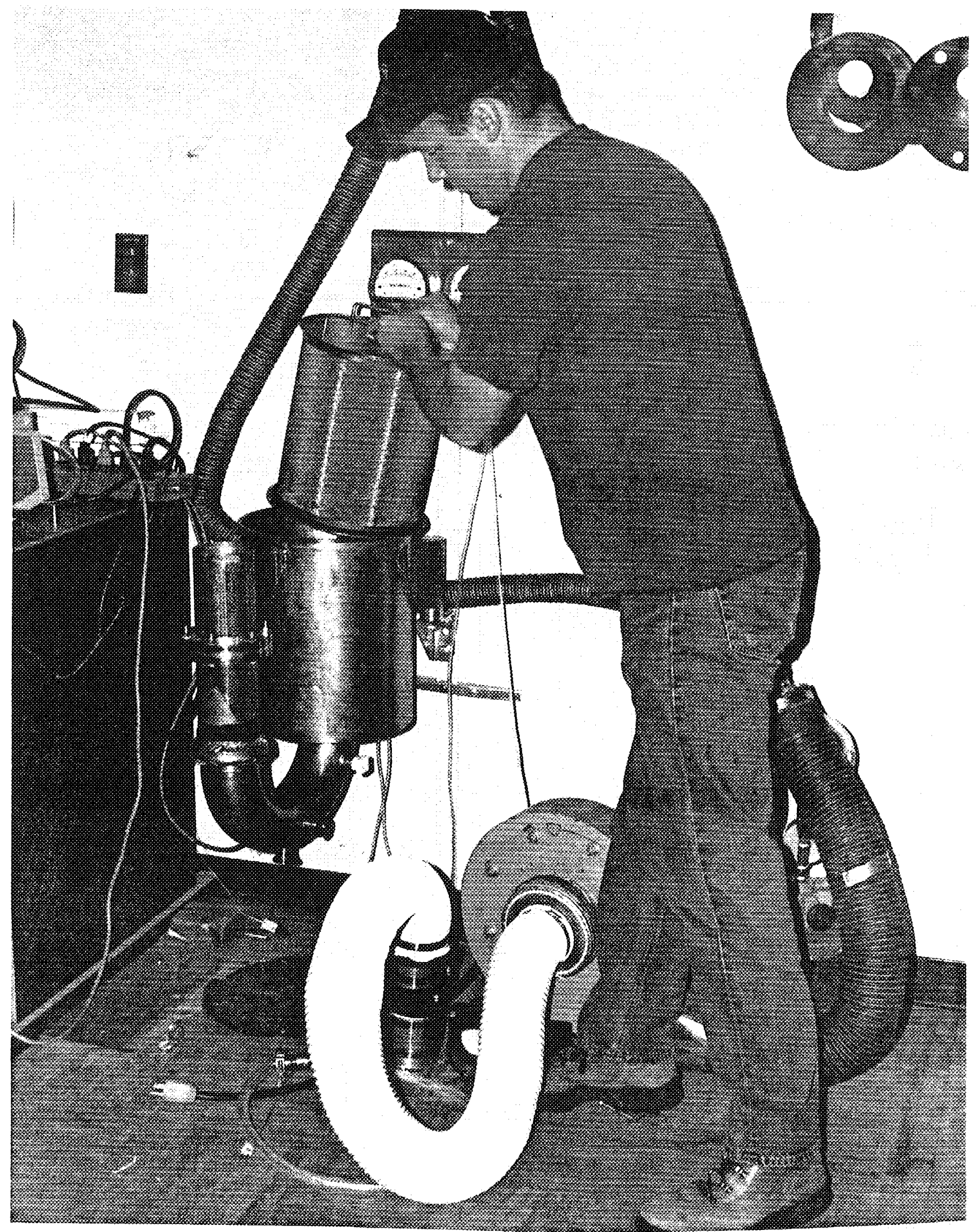

Figure 16. Photograph showing the carbon filter being inserted into the exhaust system housing. 


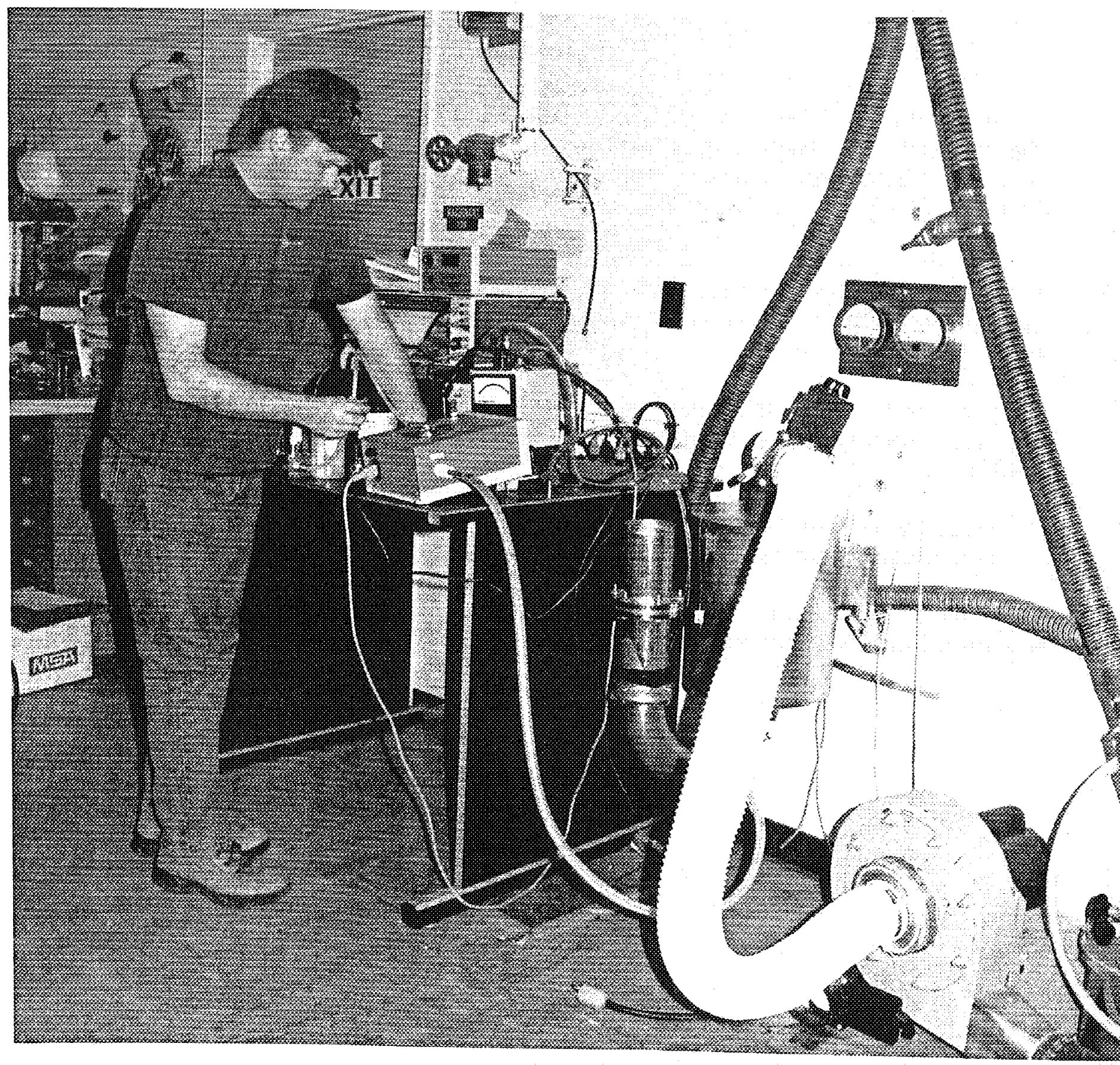

Figure 17 Photograph showing the experimental test apparatus for measuring the efficiency of the carbon filter for removing DMSO vapor. 


\section{Acknowledgment}

We gratefully acknowledge the help of Mr. Jeff Oh for designing and fabricating the carbon filter canister and to $\mathrm{Mr}$. Robert Ramos for help in testing the carbon canister.

\section{References}

1. Bergman, W, Wilson, K, Staggs, W, and Wapman, D, Lopez, R, and LeMay, J., "Degradation of HEPA filters exposed to DMSO" in Proceedings of the 24td DOE/NRC Nuclear Air Cleaning Conference, Available from NTIS, Springfield, VA, M. First, Ed., CONF 96 , pp., (1997).

2. Yoon, Y.H. and Nelson, J.H., "Application of gas adsorption kinetics: A theoretical model for respirator cartridge service life" Am. Ind. Hyg. Assoc. J. 45(8): 509-516 (1984).

3. ASME N509-1989, "Nuclear Power Plant Air-Cleaning Units and Components" American Society of Mechanical Engineers, 345 47th Street, New York, NY 10017, (1989).

4. ASME AG-1-1994, "Code on Nuclear Air and Gas Treatment", American Society of Mechanical Engineers, 34547 th Street, New York, NY 10017, (1994).

5. Martin, D., Hauthal, H.G., and Halberstadt, E.S., "Dimethly Sulfoxide", Van Nostrand Reinhold Company Ltd., Berkshire, England (1975). 